\title{
'H-Magnetic resonance spectroscopy study of stimulant medication effect on brain metabolites in French Canadian children with attention deficit hyperactivity disorder
}

\author{
This article was published in the following Dove Press journal: \\ Neuropsychiatric Disease and Treatment \\ 17 January 2014 \\ Number of times this article has been viewed
}

\author{
Leila BenAmor ${ }^{1,2}$ \\ 'Department of Psychiatry Sainte- \\ Justine Hospital, Montreal, Quebec, \\ Canada; ${ }^{2}$ Department of Psychiatry, \\ University of Montreal, Montreal, \\ Quebec, Canada
}

Background: Attention deficit hyperactivity disorder (ADHD) is a common neurodevelopmental disorder in school aged children. Functional abnormalities have been reported in brain imaging studies in ADHD populations. Psychostimulants are considered as the first line treatment for ADHD. However, little is known of the effect of stimulants on brain metabolites in ADHD patients.

Objectives: To compare the brain metabolite concentrations in children with ADHD and on stimulants with those of drug naïve children with ADHD, versus typically developed children, in a homogenous genetic sample of French Canadians.

Methods: Children with ADHD on stimulants $(n=57)$ and drug naïve children with ADHD $(n=45)$ were recruited, as well as typically developed children $(n=38)$. The presence or absence of ADHD diagnosis (Diagnostic and Statistical Manual of Mental Disorders IV criteria) was based on clinical evaluation and The Diagnostic Interview Schedule for Children IV. All children ( $\mathrm{n}=140$ ) underwent a proton magnetic resonance spectroscopy session to measure the ratio of $\mathrm{N}$-acetyl-aspartate, choline, glutamate, and glutamate-glutamine to creatine, respectively, in the left and right prefrontal and striatal regions of the brain, as well as in the left cerebellum.

Results: When compared with drug naïve children with ADHD, children with ADHD on stimulants and children typically developed were found to have higher choline ratios in the left prefrontal region $(P=0.04)$ and lower $\mathrm{N}$-acetyl-aspartate ratios in the left striatum region $(P=0.01)$, as well as lower glutamate-glutamine ratios in the left cerebellum $(P=0.05)$. In these three regions, there was no difference between children with ADHD on stimulants and typically developed children.

Conclusion: Therapeutic psychostimulant effects in children with ADHD may be mediated by normalization of brain metabolite levels, particularly in the left fronto-striato-cerebellar regions.

Keywords: attention deficit, hyperactivity, stimulants, brain, spectroscopy

\section{Introduction}

Attention deficit hyperactivity disorder (ADHD) is a common psychiatric disorder of childhood, affecting 5\%-10\% of school aged children ${ }^{1,2}$ and including symptoms of inattention and/or hyperactivity-impulsivity. ${ }^{3}$ In addition, most ADHD cases present comorbidities that include internalizing disorders, such as anxiety or depression, and externalizing disorders such as oppositional defiant disorder. ${ }^{4,5}$ ADHD is also frequently associated with sleep disorders and obesity. ${ }^{6,7}$ In $60 \%$ of cases, ADHD persists through

Sainte Justine Hospital,

Department of Psychiatry,

3175 Cote-Sainte Catherine,

Montreal (Quebec),

Canada H3TIC5.

$\mathrm{Tel}+\mathrm{I} 5$ I4 345493 I ext 3397

$\mathrm{Fax}+\mathrm{I} 5143452135$

Email leila.benamor@icloud.com 
adulthood $^{8}$ and negatively impacts the patient's family, school, and social functioning. ${ }^{9}$

Psychostimulant drugs are considered as the first line of treatment for ADHD. ${ }^{10,11}$ Two major classes of drugs are commonly indicated for ADHD: ${ }^{12}$ central nervous system stimulants and serotonin norepinephrine reuptake inhibitors. The two most commonly used drugs to treat ADHD are methylphenidate and mixed amphetamine salts. ${ }^{13}$ Methylphenidate is a blocker of, while mixed amphetamine salts is an inhibitor/ pseudosubstrate for, norepinephrine transporters in the prefrontal cortex and dopamine transporters in the striatum and nucleus accumbens (NAcc). ${ }^{12,13}$ The drugs inhibit the norepinephrine transporters activity in the prefrontal cortex and the dopamine transporters activity in the striatum and NAcc. ${ }^{13,14}$ This inhibition leads to a reduction in the reuptake of the neurotransmitter at the presynaptic neuron and results in elevated concentration of norepinephrine/dopamine in the synaptic cleft. ${ }^{13}$ The only serotonin norepinephrine reuptake inhibitor indicated for ADHD is atomoxetine, a selective inhibitor for the reuptake of norepinephrine. ${ }^{15,16}$ In comparison to stimulants, the drug has no effect on the striatum and NAcc except in the prefrontal cortex. ${ }^{12}$

Advances in brain imaging technology allow for the testing of etiological hypotheses regarding ADHD. In particular, functional magnetic resonance imaging studies have shown an altered fronto-striatal circuit in ADHD, thereby affecting the regulation of motor control, executive functions, and for the control of inhibition. ${ }^{17-20}$ Proton magnetic resonance spectroscopy ( $\left.{ }^{1} \mathrm{H}-\mathrm{MRS}\right)$ is an imaging technique that can measure the concentration of several metabolites in various brain regions during a magnetic resonance session, enabling the measurement of metabolite concentrations in different brain regions..$^{21,22}$ Despite the apparent usefulness of these new technologies, discrepancies remain among the reported brain metabolite levels in ADHD patients. Several factors may explain these disparities. To date, studies that assessed brain metabolite concentration with MRS mostly had a small sample size, ${ }^{21,23}$ did not control for the type of medication used (stimulant versus atomoxetine), or failed to report the genetic profile of study participants ${ }^{21}$ despite the importance of genetic factors in ADHD etiology. ${ }^{24}$

To better investigate the influence of stimulants in ADHD while controlling for the effect of genetics, our study aims to compare brain metabolite levels in children with ADHD who are receiving stimulant medication to drug naïve children with ADHD, as well as typically developing children, within a homogenous third generation French Canadian population.
The effect of genetic variation is limited by using a third generation homogenous population with a genetic founder effect, such as the French Canadian population. This population's founder effect (defined as a population that is initially established by a small number of families from a large population) confers a limited variation in the genetic background..$^{25,26}$

\section{Methods \\ Participants}

A total of 140 children participated in the study. One hundred and two children with a diagnosis of ADHD were recruited from the outpatient child psychiatry clinic of Hotel Dieu de Levis Hospital (Quebec, Canada). Diagnosis of ADHD was based on Diagnostic and Statistical Manual of Mental Disorders (DSM) $\mathrm{IV}^{27}$ criteria and made by experienced psychiatrists. Of those 102 children, 45 had never taken any medication to treat their ADHD (drug naïve group), whereas 57 used a psychostimulant drug (stimulant group). Thirty eight children without ADHD were recruited in the community and served as the control group (control). All participants were Caucasian and were third generation French Canadians. Children who had an intelligence quotient (IQ) below 70 (as assessed by Wechsler Intelligence Scale for Children IV or Wechsler Preschool and Primary Scale of Intelligence III) ${ }^{28}$ or who had a pervasive developmental disorder or psychosis were excluded. This study was approved by the local ethics committee, and all parents of participating children provided signed informed consent.

\section{Assessments \\ Clinical outcome}

The Diagnostic Interview Schedule for Children Version IV $(\text { DISC-IV })^{29}$ is a semistructured interview based on the DSM IV criteria. The parental version was used to obtain information on clinical ADHD characteristics, including the inattentive, hyperactive-impulsive, and total ADHD symptoms scores, the presence/absence of comorbidities, and the global functioning scores. ${ }^{29}$

\section{Brain imaging measures}

${ }^{1} \mathrm{H}$-MRS is a noninvasive technique increasingly used in the study of in vivo brain metabolites in ADHD patients. ${ }^{30}$ All patients underwent brain ${ }^{1} \mathrm{H}-\mathrm{MRS}$, performed with a GE Sigma 1.5T scanner operating at $63.85 \mathrm{MHz}$ (GE Medical Systems, Waukesha, WI, USA). The location of the voxels was determined from T1-weighted spin-echo images of an 
axial plane. Spectrums were acquired from $8.0 \mathrm{~cm}^{3}$ voxels localized in five different regions of interest: left and right prefrontal area, left and right striatal area, and left cerebellum. For voxel location, predetermined anatomical parameters were used (striatum area (Figure 1): the posterior portion of the head of caudate nucleus according to the anteroposterior axis; prefrontal area (Figure 2): over the ones determining the striatum voxels; and cerebellum (Figure 3): approximately $3 \mathrm{~mm}$ laterally from the ledge of the fourth ventricle). After each region of interest location, the GE Proton Brain Exam (PROBE) (GE Medical Systems, Waukesha, WI, USA) was followed, which comprises a suppression of the water signal with the CHESS (chemical shift selective excitation) followed by detection of the proton signal using the PRESS (point resolved spectroscopy) pulse sequence. The acquisition parameters were as follows: TR, $1500 \mathrm{~ms}$; TE, $30 \mathrm{~ms}$; number of acquisitions, 128; spectral width, 2,000 Hz; number of points, 1,024; total acquisition time, about $40 \mathrm{~min}$. With these acquisition conditions, the signal/noise ratio was 12 or more for the main signals (ranging from 12 to 28, depending on the region). The MRS data were analyzed using the LCModel software, v.6.0 (LCModel Inc., Ontario, Canada), ${ }^{31}$ and metabolite ratios for $\mathrm{N}$-acetylaspartate/creatine (NAA/Cr), choline/Cr (Cho/Cr), glutamate/Cr $(\mathrm{Glu} / \mathrm{Cr})$, and glutamate-glutamine/ $\mathrm{Cr}(\mathrm{Glx} / \mathrm{Cr})$ were calculated (Figure 4).

Before undergoing the MRS, children were invited to sessions with a MRS simulator to become familiar with the noise and conditions of the scanner.

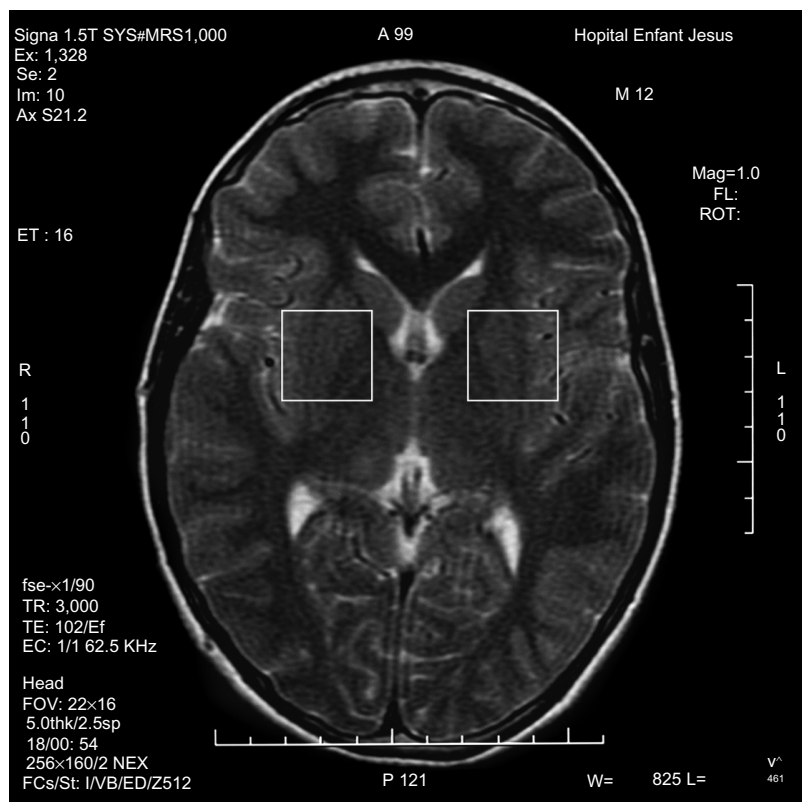

Figure I Striatal voxel localization.

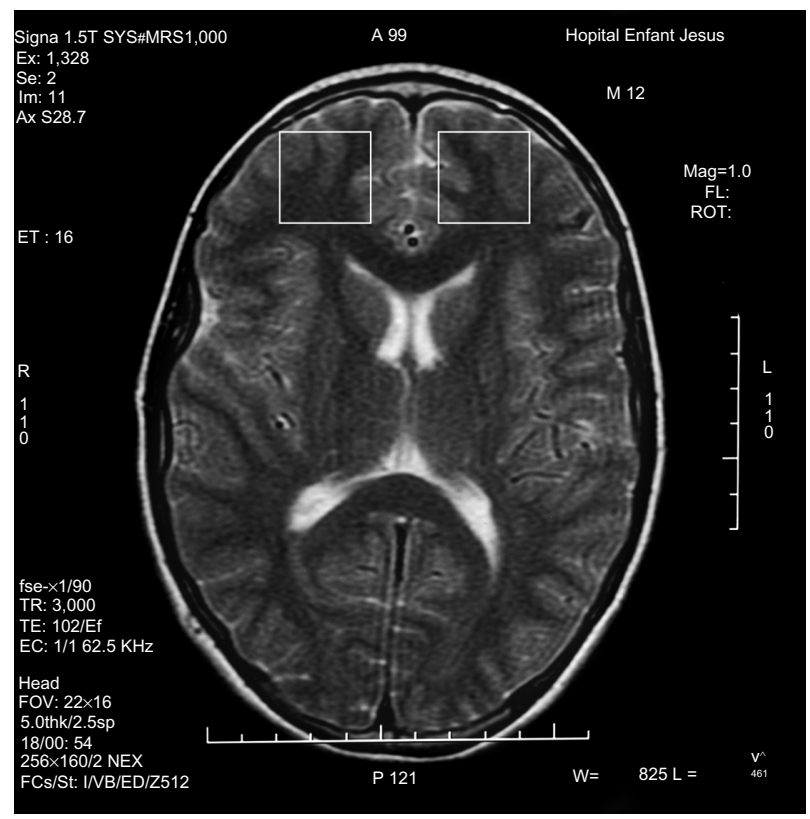

Figure 2 Prefrontal voxel localization.

\section{Statistical analysis}

We hypothesized that in children with ADHD, brain metabolite concentrations will be different between the drug naïve and the stimulant group. Analysis was performed with SPSS (v12.0; IBM Corporation, Armonk, NY, USA). Oneway analysis of variance (ANOVA) was used to compare the means of demographic, clinical, and biochemical data between the stimulant, drug naïve, and control groups. Post hoc comparisons were made with least-significant difference

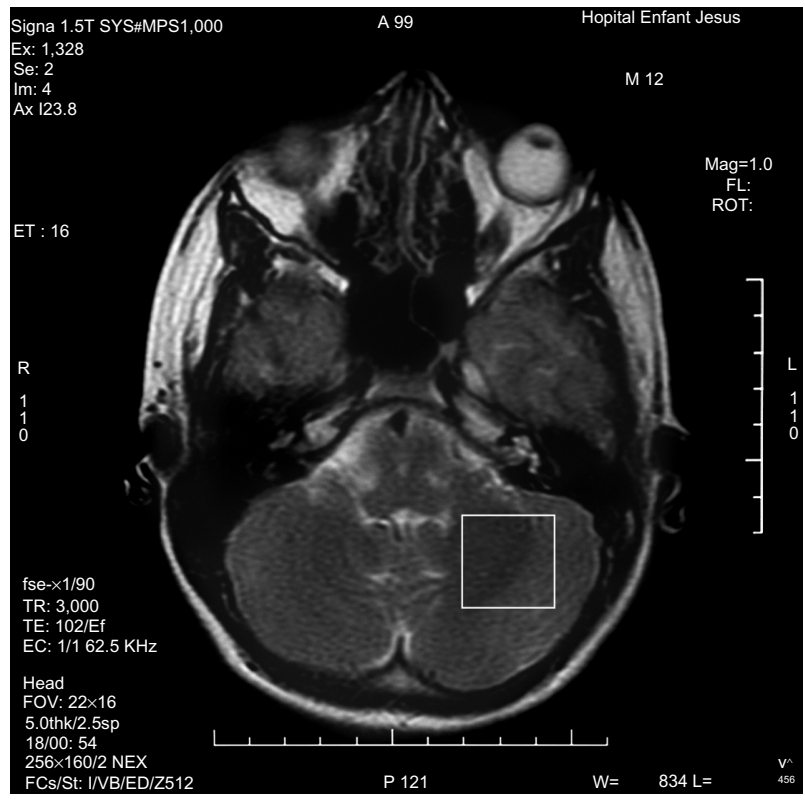

Figure 3 Left cerebellum voxel localization. 


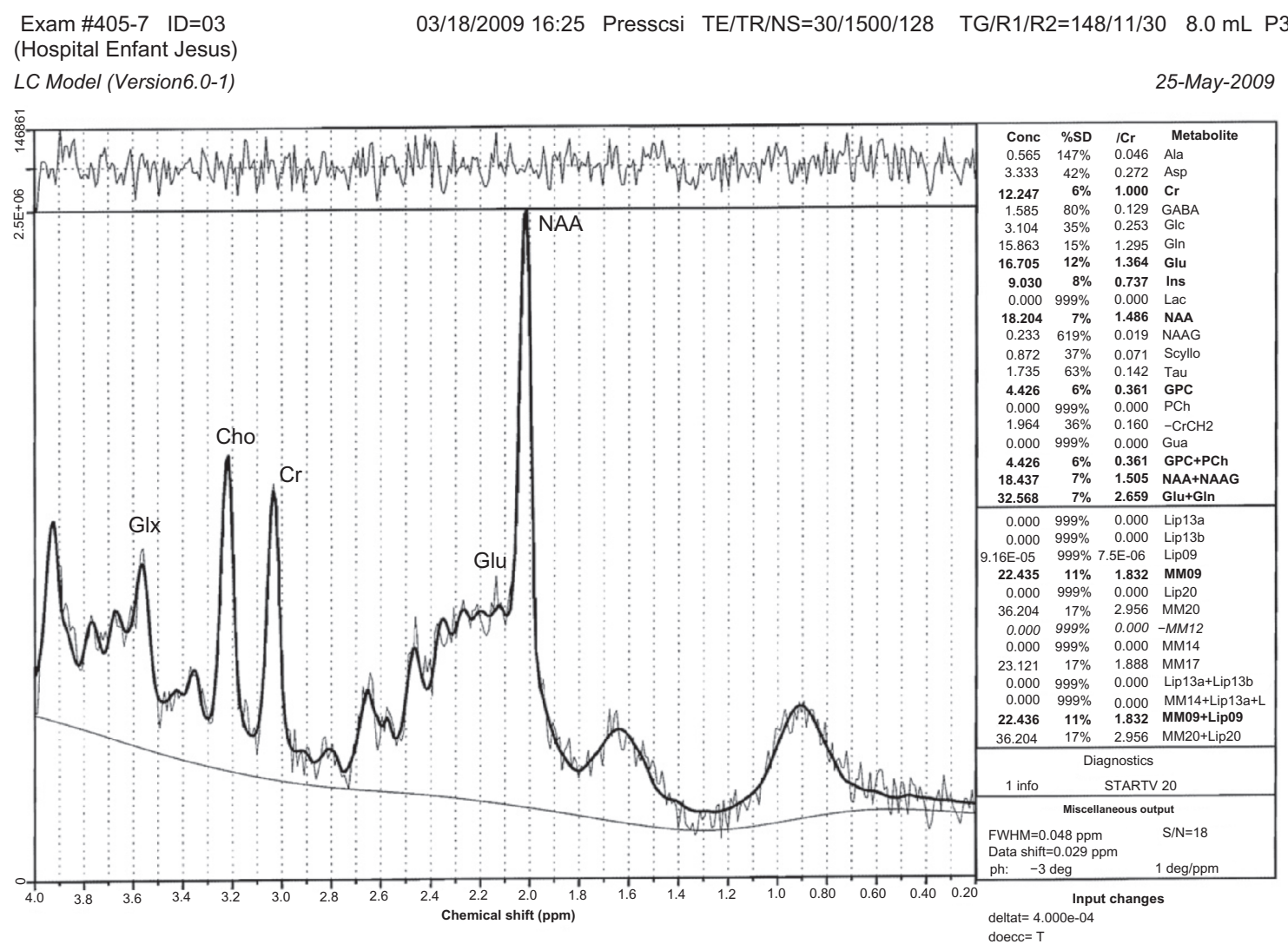

Figure 4 Example of SRM spectra.

Note: The MRS data were analyzed using the LCModel software, v.6.0 (LCModel Inc., Ontario, Canada). ${ }^{31}$

Abbreviations: Glx, glutamate-glutamine; Cho, choline; Cr, creatine; Glu, glutamate; NAA, N acetyl aspartate.

test. Frequencies of different variables between groups (eg, to compare the occurrence of a comorbidity or ratio of sex between the groups) were compared using the Pearson's chisquared test. Statistical significance was set at $P<0.05$.

\section{Results}

The three groups' demographic characteristics and clinical profiles are shown in Table 1. The age of the participants was significantly different between the groups $(F[2,137]=6.7 ; P=0.02)$. The stimulant group was on average 10.4 months older than the drug naïve group $(P=0.29)$ and 17.8 months older than the control group $(P<0.01)$. The ANOVA also revealed that the groups differed in their IQ. Post hoc analyses showed that children of the control group had higher IQ than ADHD children, whether they were drug naïve ( $P=0.01$ ) or using a psychostimulant $(P=0.004)$. The male to female ratio was equally high in all study groups (drug naïve $71 \%$, stimulant $75 \%$, and control $66 \%)(\chi=1.0 ; P=0.59)$. There was no difference in the prevalence of the different types of ADHD between drug naïve and stimulant groups $\left(\chi^{2}=0.26 ; P=0.88\right)$. In the stimulant group, $74 \%(48 / 57)$ were on methylphenidate and $16 \%(9 / 57)$ on amphetamine medication.
Table 2 summarizes how the numbers of inattentive, hyperactive, total ADHD, and impairment items measured with the DISC-IV test were significantly different between the study groups. This was an expected result, considering that children in the control group do not have ADHD. Post hoc tests revealed that both the drug naïve and the stimulant groups had a greater number of items for all four categories

Table I Clinical and socio-demographic characteristics of children with ADHD drug naïve or on stimulants and normal developing controls

\begin{tabular}{|c|c|c|c|c|}
\hline \multirow[t]{2}{*}{ Characteristics } & \multirow{2}{*}{$\begin{array}{l}\begin{array}{l}\text { Drug naïve } \\
(\mathrm{n}=45)\end{array} \\
\text { Mean (SD) }\end{array}$} & \multirow{2}{*}{$\begin{array}{l}\begin{array}{l}\text { Stimulant } \\
(\mathrm{n}=57)\end{array} \\
\text { Mean (SD) }\end{array}$} & \multirow{2}{*}{$\begin{array}{l}\begin{array}{l}\text { Control } \\
(n=38)\end{array} \\
\text { Mean (SD) }\end{array}$} & \multirow[t]{2}{*}{$P$} \\
\hline & & & & \\
\hline Age in months & $105.8(25.9)$ & $116.3(22.3)$ & $98.5(22.9)$ & 0.02 \\
\hline IQ & $98.8(13.4)$ & $98.0(13.2)$ & $106.3(14.3)$ & \\
\hline Male/female (n) & $32 / 13$ & $43 / 14$ & $25 / 13$ & 0.59 \\
\hline $\begin{array}{l}\text { ADHD type }(n) \\
(\mathrm{C} / \mathrm{l} / \mathrm{H})\end{array}$ & $31 / 13 / 1$ & $37 / 18 / 2$ & - & 0.88 \\
\hline Comorbidities (n) & & & & \\
\hline $\begin{array}{l}\text { (CD/ODD/MD/ } \\
\text { GAD) }\end{array}$ & $3 / 16 / 1 / 1$ & $3 / 19 / 2 / 2$ & $0 / 6 / 0 / 1$ & ns \\
\hline
\end{tabular}

Abbreviations: IQ, intelligence quotient; ADHD, attention deficit hyperactivity disorder; C, combined; I, inattentive; $\mathrm{H}$, hyperactive/impulsive; $\mathrm{CD}$, conduct disorder; ODD, oppositional defiant disorder; MD, major depression; GAD, generalized anxiety disorder; ns, non significant. 
Table 2 Scores on the diagnostic interview schedule for children version IV (DISC-IV) for children with ADHD drug naïve or on stimulants and normal developing controls

\begin{tabular}{|c|c|c|c|c|}
\hline & $\begin{array}{l}\text { Drug naïve } \\
(\mathrm{n}=45)\end{array}$ & $\begin{array}{l}\text { Stimulant } \\
(n=57)\end{array}$ & $\begin{array}{l}\text { Control } \\
(n=38)\end{array}$ & $F$ \\
\hline & Mean (SD) & Mean (SD) & Mean (SD) & \\
\hline Inattention & $6.6(2.3)$ & $7.1(2.0)$ & $3.1(2.7)$ & $38.7^{*}$ \\
\hline Hyperactivity & $4.8(2.9)$ & $4.5(3.0)$ & I.7 (I.8) & $16.3^{*}$ \\
\hline $\begin{array}{l}\text { Total ADHD } \\
\text { symptoms }\end{array}$ & $13.0(4.5)$ & $13.0(4.6)$ & $5.7(4.1)$ & $37.8^{*}$ \\
\hline Impairment & $7.0(3.5)$ & $9.0(4.2)$ & $3.7(3.7)$ & $21.3^{*}$ \\
\hline
\end{tabular}

Note: $* P$ values are $<0.001$.

Abbreviation: ADHD, attention deficit hyperactivity disorder.

of the DISC-IV when compared to the control children (for all comparisons, $P<0.001)$. In addition, children in the stimulant group had a significantly higher number of impairment items when compared to the drug naïve group $(P=0.01)$.

\section{MRS}

The mean metabolite ratios for the five brain regions studied are reported in Table 3. The ANOVA test revealed significant

Table 3 Mean metabolite ratios for five brain regions in children with ADHD drug naïve or on stimulants and normal developing controls

\begin{tabular}{|c|c|c|c|c|c|}
\hline & $\begin{array}{l}\text { Drug naïve } \\
(\mathrm{n}=45)\end{array}$ & $\begin{array}{l}\text { Stimulant } \\
(\mathrm{n}=57)\end{array}$ & $\begin{array}{l}\text { Control } \\
(n=38)\end{array}$ & $F$ & $P$ \\
\hline & Mean (SD) & Mean (SD) & Mean (SD) & & \\
\hline \multicolumn{6}{|c|}{ Left prefrontal cortex } \\
\hline $\mathrm{Glu} / \mathrm{Cr}$ & $\mathrm{I} .46(0.22)$ & I.37 (0.27) & $1.46(0.19)$ & 2.31 & 0.10 \\
\hline $\mathrm{Cho} / \mathrm{Cr}$ & $0.29(0.04)$ & $0.31(0.04)$ & $0.31(0.03)$ & 3.15 & 0.04 \\
\hline $\mathrm{NAA} / \mathrm{Cr}$ & $\mathrm{I} .4 \mathrm{I}(0.17)$ & $1.42(0.15)$ & $1.40(0.13)$ & 0.12 & 0.88 \\
\hline $\mathrm{Gl} / \mathrm{Cr}$ & $2.25(0.37)$ & $2.11(0.38)$ & $.25(0.32)$ & 2.38 & 0.10 \\
\hline \multicolumn{6}{|c|}{ Right prefrontal cortex } \\
\hline $\mathrm{Glu} / \mathrm{Cr}$ & $\mathrm{I} .44(0.23)$ & I. $43(0.24)$ & $1.43(0.19)$ & 0.04 & 0.96 \\
\hline $\mathrm{Cho} / \mathrm{Cr}$ & $0.36(0.37)$ & 0.31( & $0.31(0.03)$ & 0.07 & 0.93 \\
\hline $\mathrm{NAA} / \mathrm{Cr}$ & 1.43 & 39 & $4 \mid$ & 0.71 & 0.49 \\
\hline $\mathrm{Gl} / \mathrm{Cr}$ & $2.17(0.31)$ & 47) & 2.0 & 0.13 & 0.88 \\
\hline \multicolumn{6}{|l|}{ Left striatum } \\
\hline $\mathrm{Glu} / \mathrm{Cr}$ & $1.29(0.26)$ & $1.29(0.18)$ & $1.30(0.17)$ & 0.92 & 0.91 \\
\hline $\mathrm{Cho} / \mathrm{Cr}$ & $0.24(0.03)$ & $0.24(0.03)$ & $0.24(0.03)$ & 0.29 & 0.75 \\
\hline $\mathrm{NAA} / \mathrm{Cr}$ & $1.24(0.17)$ & $1.14(0.15)$ & $1.20(0.15)$ & 4.80 & 0.01 \\
\hline $\mathrm{Gl} / \mathrm{Cr}$ & 1.87 & 1.94 & 1 & 0.67 & 0.51 \\
\hline \multicolumn{6}{|c|}{ Right striatum } \\
\hline $\mathrm{Glu} / \mathrm{Cr}$ & $\mathrm{I} .34(0.27)$ & $1.27(0.18)$ & $1.25(0.19)$ & 2.29 & 0.11 \\
\hline $\mathrm{Cho} / \mathrm{Cr}$ & $0.24(0.04)$ & $0.24(0.03)$ & $0.24(0.04)$ & 0.24 & 0.79 \\
\hline $\mathrm{NAA} / \mathrm{Cr}$ & $1.23(0.19)$ & $1.16(0.15)$ & $1.21(0.17)$ & 1.80 & 0.16 \\
\hline $\mathrm{Gl} / \mathrm{Cr}$ & $2.06(0.45)$ & $1.95(0.3 \mathrm{I})$ & $1.92(0.27)$ & 1.90 & 0.15 \\
\hline \multicolumn{6}{|c|}{ Left cerebellum } \\
\hline $\mathrm{Glu} / \mathrm{Cr}$ & $0.98(0.18)$ & $0.99(0.2 \mathrm{I})$ & $0.96(0.24)$ & 0.18 & 0.83 \\
\hline $\mathrm{Cho} / \mathrm{Cr}$ & $0.26(0.03)$ & $0.26(0.03)$ & $0.26(0.03)$ & 0.35 & 0.71 \\
\hline $\mathrm{NAA} / \mathrm{Cr}$ & $1.07(0.16)$ & $\mathrm{I} .06(0.2 \mathrm{I})$ & $1.09(0.21)$ & 0.29 & 0.75 \\
\hline $\mathrm{GIx} / \mathrm{Cr}$ & $1.73(0.48)$ & $1.56(0.33)$ & $1.53(0.40)$ & 2.96 & 0.05 \\
\hline
\end{tabular}

Abbreviations: $A D H D$, attention deficit hyperactivity disorder; $\mathrm{Glu} / \mathrm{Cr}$, ratio glutamate/creatine; $\mathrm{Cho} / \mathrm{Cr}$, ratio choline/creatine; $\mathrm{NAA} / \mathrm{Cr}$, ratio $\mathrm{N}$-acetylaspartate/ creatine; Glx, ratio glutamate+glutamine/creatine. differences between the groups in choline ratios in the left prefrontal cortex $(F[2,135]=3.1 ; P=0.04)$. Post hoc tests confirmed that the choline ratio was lower in the drug naïve group when compared with the stimulant $(P=0.03)$ and the control $(P=0.02)$ groups. In the left striatum, the ratio of NAA was also significantly different between groups $(F[2,135]=4.8$; $P=0.01)$. Between group comparisons showed that the NAA level was lower in the stimulant group when compared with the drug naïve group $(P=0.003)$. Although the result was not statistically significant $(F[2,128]=2.96 ; P=0.05)$, ANOVA results suggest that the $\mathrm{Glx} / \mathrm{Cr}$ ratio in the left cerebellum may also be different between groups. As observed in the two other brain regions, there is a tendency for comparable metabolite ratios between the stimulant and the control groups, and this could be significantly different from the drug naïve group.

\section{Discussion}

The strength of our study is related to the larger sample size when compared with existing literature, the limited genetic variation in the groups studied, as well as the comparison of three groups of children (normal, with ADHD drug naïve, and with ADHD under stimulants). In our study, drug naïve children with ADHD showed changes in specific metabolite ratios in left fronto-striato-cerebellar regions when compared to both children with ADHD on stimulants and with typically developed children. No difference was found in those metabolite ratios and brain regions between children with ADHD on stimulants and the control children. Both children with ADHD on stimulants and children without ADHD showed higher choline ratios in the left prefrontal cortex when compared to drug naïve children with ADHD.

To our knowledge, two studies ${ }^{32,33}$ reported changes in $\mathrm{Cho} / \mathrm{Cr}$ ratio in the prefrontal area in ADHD children. Interestingly, these two studies had been conducted in two different genetically defined populations.

In a recent prospective study in Indonesia, Wiguna and coauthors found significant neurochemical changes in the prefrontal cortices of children with ADHD. ${ }^{32}$ They used ${ }^{1} \mathrm{H}-\mathrm{MRS}$ to assess changes in metabolites in both the right and left prefrontal cortex in children with ADHD, after administration of long acting methylphenidate for 12 weeks. They reported that the $\mathrm{Cho} / \mathrm{Cr}$ ratio decreased significantly in the right and the left prefrontal cortex. They also reported that the $\mathrm{Glu} / \mathrm{Cr}$ ratio decreased in the right and the left prefrontal cortex, and that the $\mathrm{mI} / \mathrm{Cr}$ ratio decreased significantly only in the left prefrontal cortex. They found an increase in the $\mathrm{NAA} / \mathrm{Cr}$ ratio in the right and the left prefrontal cortex. ${ }^{32}$ 
These differences with our current results may be explained by the differences in treatment duration and methylphenidate (specifically long acting) treatment (with amphetamines in our study versus without amphetamines in the Wiguna et $\mathrm{al}^{32}$ study). It is also important to mention that the differences with our results could be explained by the genetic background of our samples.

The second study found an increase in $\mathrm{Cho} / \mathrm{Cr}$ in the right frontal area (also an increase in $\mathrm{Glu} / \mathrm{Cr}$ and NAA/Cr and a decrease of $\mathrm{Cr}$ in the right frontal area as well as an increase in $\mathrm{Glu} / \mathrm{Cr}$ in the left frontal lobe), by comparing eight hyperactive ADHD patients (aged 6 to 12 years) to eight control children, while controlling for age, sex, ethnicity (Caucasian) and IQ. ${ }^{33}$ All ADHD patients had stopped taking their medications (stimulants, especially Ritalin) 24 hours before the magnetic resonance imaging. ${ }^{33}$ To our knowledge this is the only study that takes into account ethnicity, thus limiting somewhat the genetic heterogeneity. However, the sample size is small and the effectiveness of the washout could not be determined.

Choline is a component of the cell membrane and an indicator of myelination and turnover of cell membranes. It has been suggested that changes in choline concentration in ADHD fits with the energetic hypothesis of ADHD. ${ }^{34}$ In this hypothesis, ADHD cognitive dysfunction arises from inefficient and inconsistent neuronal transmission of information, due to a deficient energy supply - lactate production - by the astrocytes, the major nonneuronal component of the central nervous system. ${ }^{34}$

Furthermore, variations in NAA are often associated with ADHD. The NAA is often considered a marker of neuronal viability; ${ }^{30}$ it is also associated with energy metabolism in the brain as it is produced in the mitochondria. ${ }^{35}$ Parallel to this, some preclinical studies in young rats have shown that methylphenidate affects the brain's metabolic energy. ${ }^{36}$ In our study, the decrease in the NAA/Cr ratio in the left striatum in both children with ADHD on stimulants and in normal controls when compared with the drug naïve group fits with the energetic hypothesis of ADHD. ${ }^{34}$ Reported metabolite levels measured by ${ }^{1} \mathrm{H}-\mathrm{MRS}$ in the left striatum have also been inconsistent. ${ }^{23,37,38}$ Studies have reported differences in NAA, Glx, and $\mathrm{Cr}$ in the striatum when compared between ADHD and typically developed children. ${ }^{23,37,38}$

As the cerebellum is involved in cognitive functions such as attention, language, memory, and executive functions, ${ }^{39}$ as well as adaptation of motor function, ${ }^{40,41}$ it is a major region of interest in ADHD studies. Results of this study demonstrated a lower ratio of $\mathrm{Glx} / \mathrm{Cr}$ in the left cerebellum of the stimulant group when compared with the drug naïve group. Glutamate is a very important excitatory neurotransmitter in the cortico-striato-cerebellar circuit. ${ }^{42}$ MRS studies in humans show that $70 \%-80 \%$ of glucose consumption is used to feed the cycle of glutamate in the resting brain. ${ }^{43}$

In addition, Perlov et $\mathrm{al}^{44}$ found an increase in $\mathrm{Glx} / \mathrm{Cr}$ in the left cerebellum in adults with ADHD, while Soliva and collaborators reported other metabolite (NAA and myoinositol) changes in that same area in ADHD children who were medicated. ${ }^{45}$ Not only does this combination of findings support the significant role of the left cerebellum in ADHD, they also suggest that differences in brain metabolites may be related to the energetic etiology of ADHD.

The results of our study should be interpreted taking into account the limitations of our study. The first limitation is the grouping of different stimulants (methylphenidate and amphetamine salts), as well as the variability in treatment durations in the stimulant group. The second limitation is the differences in the age and IQ between our three groups; these differences may interfere with brain metabolite data. However, we performed analysis of covariance with age as a covariable, and there were no changes in any of the metabolite ratio results. We performed the same analysis with IQ as a covariable, and the only change found was a decrease in the difference between the $\mathrm{Cho} / \mathrm{Cr}$ ratios in the prefrontal area between the three groups $(P=0.08)$. However, $\mathrm{Cho} / \mathrm{Cr}$ ratios in the prefrontal area between children with ADHD on stimulants and those who were drug naïve is still statistically significant $(P=0.02)$, as well as the difference between children with ADHD on stimulants and the controls $(P=0.03)$. Finally, in the ANOVA analysis we did not correct for multiple comparisons to minimize the type II errors, but this might increase type I error.

\section{Conclusion}

The results of our study show that groups of children with ADHD from a genetically homogenous French Canadian population and who have never taken any medication, have different brain biochemical characteristics when compared with those on stimulants. Such differences do not exist between children with ADHD on stimulants and typically developed children.

Therefore, stimulants appear to restore the concentration of choline in the prefrontal cortex, NAA in the striatum, as well as glutamate in the cerebellum. It is therefore important to continue investigating the role of each of the metabolites studied in ADHD etiology to better understand the effect of medication on neurobiological functioning. 


\section{Acknowledgment}

The author would like to thank Sophie Chantal $\mathrm{PhD}$ for her contribution in the spectroscopy part of this study.

\section{Disclosure}

This work has been supported by a research grant to L BenAmor from the Canadian Institute to Health Research.

\section{References}

1. Biederman J, Faraone S. Attention-deficit hyperactivity disorder. Lancet. 2005;366(9481):237-248.

2. Faraone S, Sergeant J, Gillberg C, Biederman J. The worldwide prevalence of ADHD: is it an American condition? World Psychiatry. 2003;2(2):104-113.

3. Swanson JM, Sergeant JA, Taylor E, Sonuga Barke EJ, Jensen PS, Cantwell DP. Attention-deficit hyperactivity disorder and hyperkinetic disorder. Lancet. 1998;351(9100):429-433.

4. Mannuzza S, Klein RG, Bessler A, Malloy P, Hynes ME. Educational and occupational outcome of hyperactive boys grown up. J Am Acad Child Adolesc Psychiatry. 1997;36(9):1222-1227.

5. Mannuzza S, Klein RG, Bessler A, Malloy P, LaPadula M. Adult psychiatric status of hyperactive boys grown up. Am J Psychiatry. 1998;155(4):493-498.

6. Schwartz S, Ben Amor L, Grizenko N, et al. Actigraphic monitoring during sleep of children with ADHD on methylphenidate and placebo. J Am Acad Child Adolesc Psychiatry. 2004;43(10):1276-1282.

7. Cortese S, Vincenzi B. Obesity and ADHD: clinical and neurobiological implications. Curr Top Behav Neurosci. 2012;9:199-218.

8. Faraone SV, Biederman J, Spencer T, et al. Attention-deficit/hyperactivity disorder in adults: an overview. Biol Psychiatry. 2000;48(1):9-20.

9. Barkley R, Fischer M, Smallish L, Fletcher K. Young adult outcome of hyperactive children: adaptive functioning in major life activities. J Am Acad Child Adolesc Psychiatry. 2006;45(2):192-202.

10. Pliszka S; AACAP Work Group on Quality Issues. Practice parameter for the assessment and treatment of children and adolescents with attention-deficit/hyperactivity disorder. J Am Acad Child Adolesc Psychiatry. 2007;46(7):894-921.

11. Faraone S, Biederman J, Spencer T, Aleardi M. Comparing the efficacy of medications for ADHD using meta-analysis. Med Gen Med. 2006;8(4):4.

12. Stahl SM. Stahl's Essential Psychopharmacology: Neuroscientific Basis and Practical Applications. 3rd edition. New York: Cambridge University Press; 2008:863-897.

13. Elia J, Ambrosini PJ, Rapoport JL. Treatment of attention-deficithyperactivity disorder. N Engl J Med. 1999;340(10):780-788.

14. McDonagh MS, Peterson K, Dana T, Thakurta S. Drug Class Review on Pharmacologic Treatment for ADHD: Final Report. Portland: Oregon Health \& Science University; 2007.

15. Barton J. Atomoxetine: a new pharmacotherapeutic approach in the management of attention deficit/hyperactivity disorder. Arch Dis Child. 2005;90(Suppl 1):i26-i29.

16. Corman S, Fedutes B, Culley C. Atomoxetine: the first nonstimulant for the management of attention-deficit/hyperactivity disorder. $\mathrm{Am} \mathrm{J}$ Health Syst Pharm. 2004;61(22):2391-2399.

17. Castellanos FX, Sonuga-Barke EJ, Milham MP, Tannock R. Characterizing cognition in ADHD: beyond executive dysfunction. Trends Cogn Sci. 2006;10(3):117-123.

18. Giedd JN, Blumenthal J, Molloy E, Castellanos FX. Brain imaging of attention deficit/hyperactivity disorder. Ann N Y Acad Sci. 2001;931: 33-49.

19. Rapoport JL, Castellanos FX, Gogate N, Janson K, Kohler S, Nelson P. Imaging normal and abnormal brain development: new perspectives for child psychiatry. Aust N Z J Psychiatry. 2001;35(3):272-281.
20. Rubia K, Overmeyer S, Taylor E, et al. Functional frontalisation with age: mapping neurodevelopmental trajectories with fMRI. Neurosci Biobehav Rev. 2000;24(1):13-19.

21. Malhi G, Valenzuela M, Wen W, Sachdev P. Magnetic resonance spectroscopy and its applications in psychiatry. Aust N ZJ Psychiatry. 2002;36(1):31-43.

22. Bush G, Valera E, Seidman L. Functional neuroimaging of attentiondeficit/hyperactivity disorder: a review and suggested future directions. Biol Psychiatry. 2005;57(11):1273-1284.

23. MacMaster F, Carrey N, Sparkes S, Kusumakar V. Proton spectroscopy in medication-free pediatric attention-deficit/hyperactivity disorder. Biol Psychiatry. 2003;53(2):184-187.

24. Acosta M, Arcos Burgos M, Muenke M. Attention deficit/hyperactivity disorder (ADHD): complex phenotype, simple genotype? Genet Med. 2004;6(1):1-15

25. De Braekeleer M. Hereditary disorders in Saguenay-Lac-St-Jean (Quebec, Canada). Hum Hered. 1991;41(3):141-146.

26. Laberge AM, Michaud J, Richter A, et al. Population history and its impact on medical genetics in Quebec. Clin Genet. 2005;68(4):287-301.

27. American Psychiatric Association, editor. Diagnostic and Statistical Manual of Mental Disorders, Fourth Edition: DSM-IV. Washington: American Psychiatric Association; 1994.

28. Baron I. Test review: Wechsler Intelligence Scale for Children-Fourth Edition (WISC-IV). Child Neuropsychol. 2005;11(5):471-475.

29. Shaffer D, Fisher P, Lucas CP, Dulcan MK, Schwab Stone ME. NIMH Diagnostic Interview Schedule for Children Version IV (NIMH DISC-IV): description, differences from previous versions, and reliability of some common diagnoses. Am Acad Child Adolesc Psychiatry. 2000;39(1):28-38.

30. Sparkes SJ, MacMaster FP, Carrey NC. Proton magnetic resonance spectroscopy and cognitive function in pediatric attention-deficit/ hyperactive disorder. Brain Cogn. 2004;54(2):173-175.

31. Provencher SW. Estimation of metabolite concentrations from localized in vivo proton NMR spectra. Magn Reson Med. 1993;30(6):672-679.

32. Wiguna T, Guerrero APS, Wibisono S, Sastroasmoro S. Effect of 12-week administration of 20-mg long-acting methylphenidate on $\mathrm{Glu} / \mathrm{Cr}, \mathrm{NAA} / \mathrm{Cr}, \mathrm{Cho} / \mathrm{Cr}$, and $\mathrm{mI} / \mathrm{Cr}$ ratios in the prefrontal cortices of school-age children in Indonesia: a study using $1 \mathrm{H}$ magnetic resonance spectroscopy (MRS). Clin Neuropharmacol. 35(2):81-85.

33. Courvoisie H, Hooper S, Fine C, Kwock L, Castillo M. Neurometabolic functioning and neuropsychological correlates in children with ADHD-H: preliminary findings. Neuropsychiatry Clin Neurosci. 2004;16(1):63-69.

34. Russell VA, Oades RD, Tannock R, et al. Response variability in Attention-Deficit/Hyperactivity Disorder: a neuronal and glial energetics hypothesis. Behav Brain Funct. 2006;2:30.

35. Clark JB. N-acetyl aspartate: a marker for neuronal loss or mitochondrial dysfunction. Dev Neurosci. 1998;20(4-5):271-276.

36. Martins MR, Reinke A, Petronilho FC, Gomes KM, Dal Pizzol F, Quevedo J. Methylphenidate treatment induces oxidative stress in young rat brain. Brain Res. 2006;1078(1):189-197.

37. Carrey N, MacMaster F, Fogel J, et al. Metabolite changes resulting from treatment in children with ADHD: a $1 \mathrm{H}-\mathrm{MRS}$ study. Clin Neuropharmacol. 2003;26(4):218-221.

38. Carrey NJ, MacMaster FP, Gaudet L, Schmidt MH. Striatal creatine and glutamate/glutamine in attention-deficit/hyperactivity disorder. J Child Adolesc Psychopharmacol. 2007;17(1):11-17.

39. Baldacara L, Borgio JG, Lacerda AL, Jackowski AP. Cerebellum and psychiatric disorders. Rev Bras Psiuiatr. 2008;30(3):281-289.

40. Schmahmann JD. Disorders of the cerebellum: ataxia, dysmetria of thought, and the cerebellar cognitive affective syndrome. J Neuropsychiatry Clin Neurosci. 2004;16(3):367-378.

41. Townsend J, Courchesne E, Covington J, et al. Spatial attention deficits in patients with acquired or developmental cerebellar abnormality. J Neurosci. 1999;19(13):5632-5643.

42. Shulman RG. Functional imaging studies: linking mind and basic neuroscience. Am J Psychiatry. 2001;158(1):11-20. 
43. Sibson NR, Dhankhar A, Mason GF, Rothman DL, Behar KL, Shulman RG. Stoichiometric coupling of brain glucose metabolism and glutamatergic neuronal activity. Proc Natl Acad Sci U S A. 1998;95(1):316-321.

44. Perlov E, Tebarzt van Elst L, Buechert M, et al. $\mathrm{H}^{1}$-MR-spectroscopy of cerebellum in adult attention deficit/hyperactivity disorder. J Psychiatr Res. 2010;44(14):938-943.
45. Soliva JC, Moreno A, Fauquet J, et al. Cerebellar neurometabolite abnormalities in pediatric attention/deficit hyperactivity disorder: a proton MR spectroscopic study. Neurosci Let. 2010;470(1):60-64.

\section{Publish your work in this journal}

Neuropsychiatric Disease and Treatment is an international, peerreviewed journal of clinical therapeutics and pharmacology focusing on concise rapid reporting of clinical or pre-clinical studies on a range of neuropsychiatric and neurological disorders. This journal is indexed on PubMed Central, the 'PsycINFO' database and CAS.

The manuscript management system is completely online and includes a very quick and fair peer-review system, which is all easy to use. Visit http://www.dovepress.com/testimonials.php to read real quotes from published authors.

\footnotetext{
Submit your manuscript here: http://www.dovepress.com/neuropsychiatric-disease-and-treatment-journal
} 